\title{
Computer Modal Analysis of Rotating Machinery under Complex Conditions
}

\author{
Jiangang $\mathrm{Yi}^{1,2, a}{ }^{*}$, Qianpeng $\operatorname{Han}^{2, \mathrm{~b}}$ \\ ${ }^{1}$ Hubei Key Laboratory of Industrial Fume \& Dust Pollution Control, Jianghan University, Wuhan, \\ China \\ ${ }^{2}$ School of Electromechanical and Architectural Engineering, Jianghan University, Wuhan, China \\ a yjg_wh@yeah.net, ${ }^{b}$ mytemp518@126.com
}

Keywords: Computer Modal Analysis, Complex Conditions, Rotating Machinery, Computer Simulation.

Abstract. Due to the influence of the working environment, there is always unbalance fault in rotating machinery which is difficult to detect by sensors. In order to solve this problem, the unbalanced rotor model is established by using modal analysis theory in this paper. The first six mode shapes of the simulated rotor were analyzed. Based on it, the simulation model of mildly unbalanced rotor system was established and the relationships between the natural frequency and the rotor vibration mode were built. The experimental result shows the proposed model is effective for rotor unbalance evaluation of industrial dust blower under complex condition.

\section{Introduction}

Industrial dust blower is worked under complex conditions such as high temperature, heavy load and high rotating speed. In this bad circumstance, there always brings some faults in rotating machinery such as industrial dust blower. In the beginning of most of the faults, there often emerges mild unbalance phenomenon which can hardly be detected. However, if this kind of faults is not detected timely, it may cause more severe production problem and device faults. Therefore, it is of great importance to study rotor unbalance fault of industrial dust blower under the complex conditions. Modal analysis is an effective method for studying the dynamic characteristics of system, which is used to identify the modal parameters, analyze the vibration characteristics, and forecast faults types [1].

\section{System Modeling}

Figure 1 shows an unbalanced rotor which is used in large scale dust blower machinery. Because of the complex conditions such as heavy load, high temperature and high rotating speed, it is always in some abnormal condition. It is estimated that rotor unbalancing is the main fault which causes heavy traffics [2]. However, the unbalance phenomenon in early time cannot be monitored by sensors [3, 4, 5].To detect the influence factors of unbalanced rotor, the finite element rotor dynamics simulation model is established by NASTRAN software.

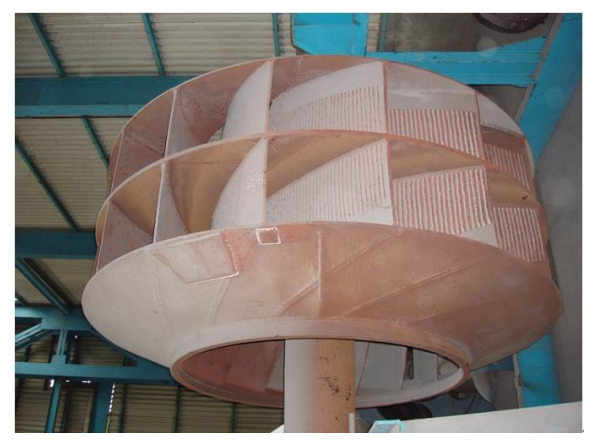

Fig. 1: The unbalanced rotor

With the working parameters of an industrial dust blower rotor shown in Table 1, the rotor model is established by computer simulation, and its modal shapes under normal conditions and abnormal 
conditions of mildly unbalanced rotor are analyzed. The first six modes of industrial dust blower rotor under normal conditions and abnormal conditions are shown in Figure 2 to Figure 7.

Table 1: The working parameters of rotor

\begin{tabular}{l|l}
\hline \hline Material & $16 \mathrm{Mn}$ \\
\hline Rotor length & $6000 \mathrm{~mm}$ \\
\hline Diameter & $2500 \mathrm{~mm}$ \\
\hline Weight & $21500 \mathrm{Kg}$ \\
\hline Width of leaf & $650 \mathrm{~mm}$ \\
\hline Leaf length & $700 \mathrm{~mm}$ \\
\hline Blade thickness & $25 \mathrm{~mm}$ \\
\hline Impeller thickness & $20 \mathrm{~mm}$ \\
\hline Rated speed & $1200 \mathrm{RPM}$ \\
\hline \hline
\end{tabular}

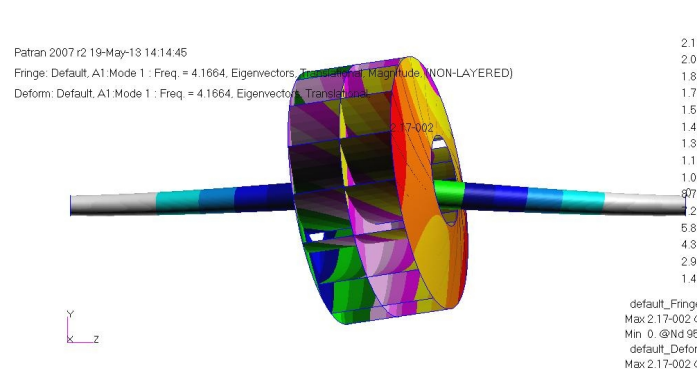

(a) Under normal conditions

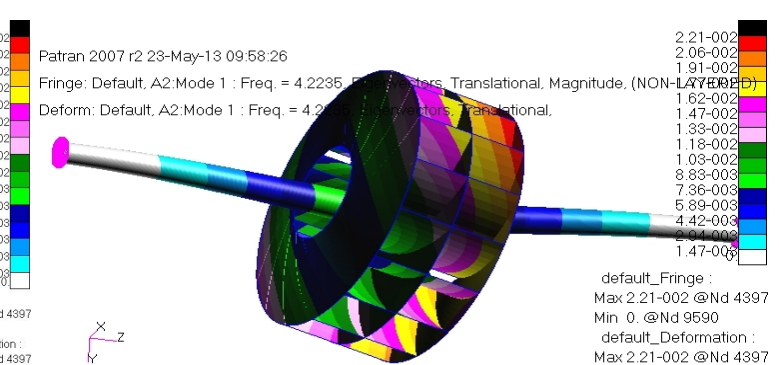

(b) Under abnormal conditions

Fig. 2: The first order model of rotor system

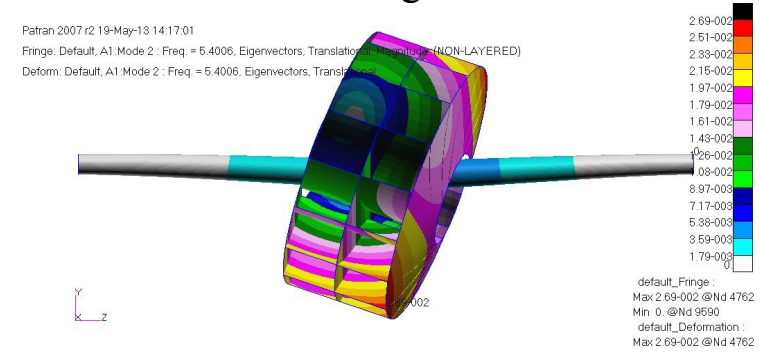

(a) Under normal conditions

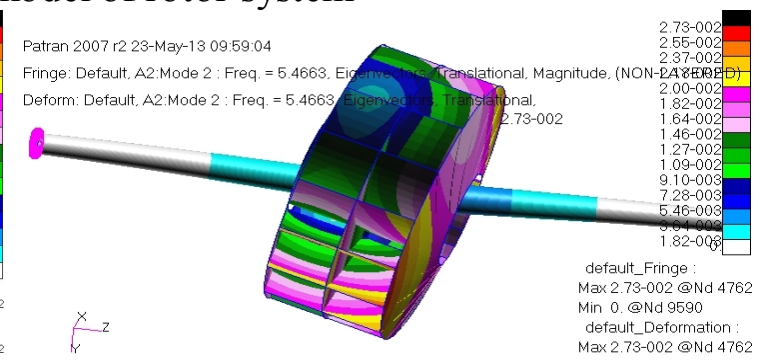

(b) Under abnormal conditions

Fig. 3: The second order model of rotor system

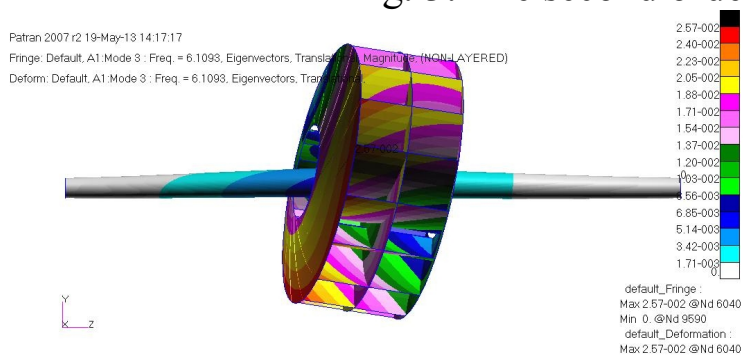

(a) Under normal conditions

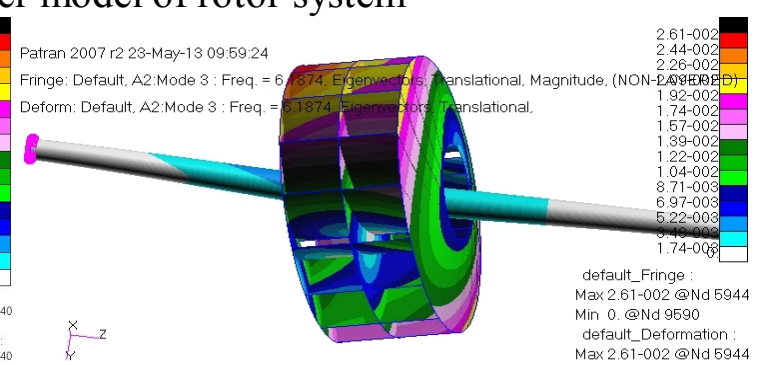

(b) Under abnormal conditions

Fig. 4: The third order model of rotor system

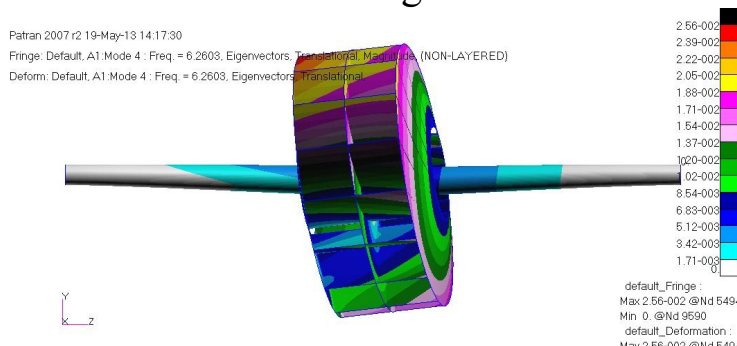

(a) Under normal conditions

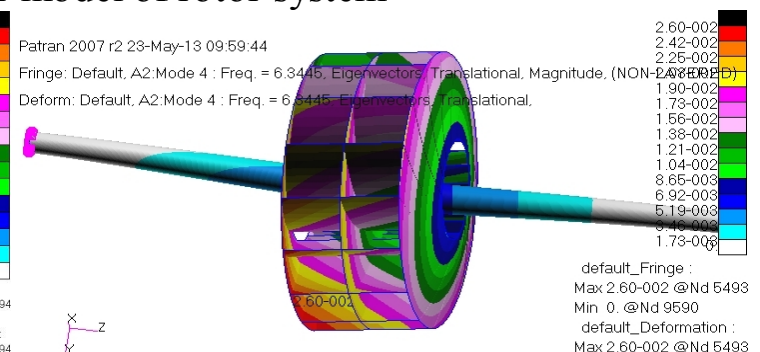

(b) Under abnormal conditions

Fig. 5: The fourth order model of rotor system 


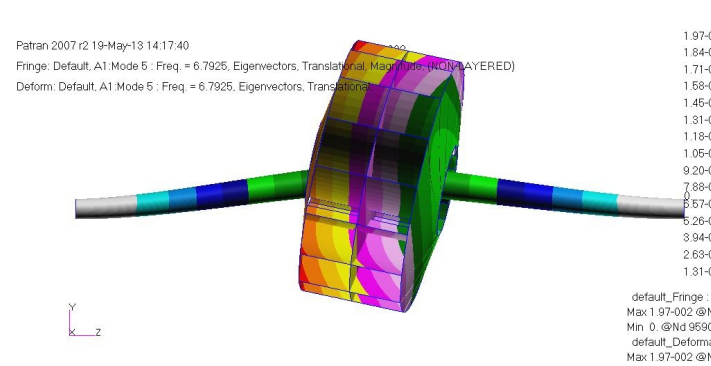

(a) Under normal conditions

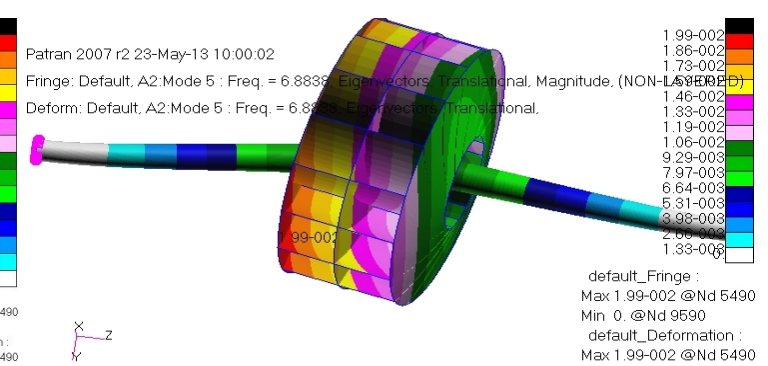

(b) Under abnormal conditions

Fig. 6: The fifth order model of rotor system

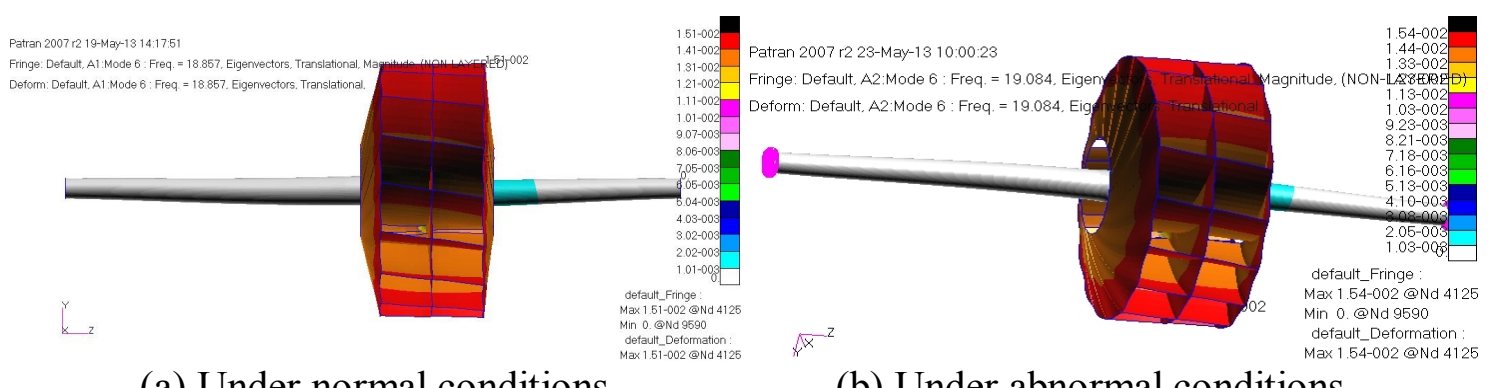

(a) Under normal conditions

(b) Under abnormal conditions

Fig. 7: The six order model of rotor system

\section{Experimental Results}

According to the established unbalanced rotor dynamics modal, we finished the mildly unbalanced calculation model by using Matlab software to analyze the early fault information contained in the different mode shapes of the rotor system, as shown in Figure 8. In actual working environment, there are too many factors influencing the fault detection of the rotor system. In order to reduce the calculation complexity of the model, the rotor unbalance is simplified as a mass added at some position of rotor coordinate system.

Table 2: The simulation results

\begin{tabular}{c|c|c|c|c|c|c|c}
\hline \hline Order & $\begin{array}{c}\text { Original } \\
(\mathrm{Hz})\end{array}$ & $10^{5}$ & $10^{6}$ & $10^{7}$ & $10^{8}$ & $10^{9}$ & $10^{10}$ \\
\hline First & 4.17 & 0.90 & 2.36 & 3.56 & 3.90 & 3.92 & 3.92 \\
\hline Second & 5.40 & 0.90 & 2.40 & 3.67 & 4.10 & 5.03 & 5.34 \\
\hline Third & 6.11 & 0.92 & 2.89 & 5.74 & 5.97 & 5.99 & 5.99 \\
\hline Fourth & 6.26 & 4.80 & 5.07 & 5.74 & 6.02 & 6.09 & 6.09 \\
\hline Fifth & 6.79 & 4.82 & 5.07 & 6.02 & 6.07 & 6.29 & 6.59 \\
\hline Sixth & 18.86 & 6.00 & 6.00 & 8.37 & 15.98 & 18.44 & 18.77 \\
\hline \hline
\end{tabular}

In terms of the working parameters shown in Table 1, the rotor unbalance vibration modals of the first to the six order are calculated. The calculation results are shown in Table 2. According to Table 2, with the change of the rotor vibration model, it can be seen the frequencies of the first five order modals are changed slightly, which indicates the slight vibration of the rotation rotor under low frequency has little influence to system balance. However, the change of the six modal of the rotor is obvious, which indicates the maximum vibration locates at the position of the blade edge of the rotor system, where the blade fracture or the system noise is easy to be produced. In this case, we should strengthen the monitoring of industrial dust blower blades to avoid failure. After checking, we find there has local wear of the rotor blades which lead to slight unbalance. With the coupled amplifier of high rotor rotating speed, the mild unbalance results in larger edge jitter of rotor blade. Therefore, the established model is used to calculate the minimum unbalance mass and evaluate sensor arrangement positions. By 
welding a piece of mass weighted $2 \mathrm{Kg}$ at the outer edge of the rotor, we successfully resolve the mild unbalance rotor problem.

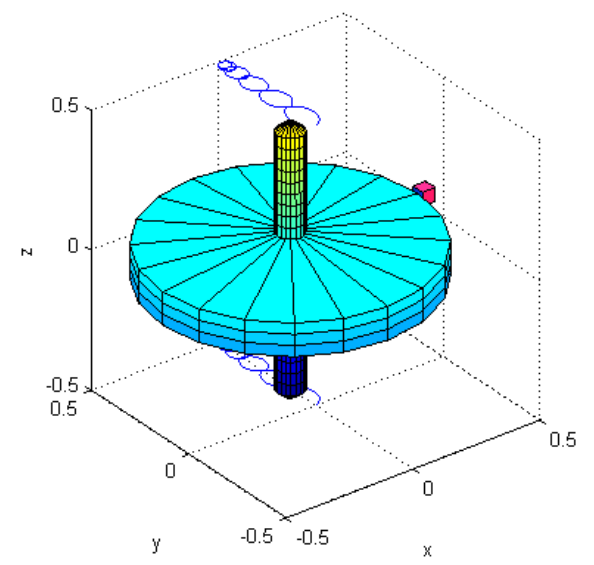

Fig. 8: The calculation model of unbalanced rotor

\section{Conclusions}

It is difficult to detect the unbalance fault in the beginning time of mechanical device. In this paper, we proposed a modal analysis method and established the mode shapes of unbalanced rotor of industrial dust blower under complicated conditions. The results show that the local wear leads to mild unbalance fault, which can be calculated by the presented approach. Meanwhile, the repairing location can be evaluated, which is greatly useful for equipment management.

\section{Acknowledgment}

This work is supported by Industry-university-research project of Wuhan Education Bureau (Granted No: cxy02) and the open project of Hubei Key Laboratory of Industrial Fume \& Dust Pollution Control (Granted No: HBIK2014-05), China. The authors also gratefully acknowledge the helpful comments and suggestions of the reviewers, which have improved the presentation.

\section{References}

[1] Zhou Linren, Ou Jinping. Study of parameters selection in finite element model updating based on parameter correction. ICIC Express Letters, 4(2010), 1831-1837.

[2] Mersinligil Mehmet, Brouckaert Jean-Franois, Courtiade Nicolas, Ottavy Xavier. A high temperature high bandwidth fast response total pressure probe for measurements in a multistage axial compressor. Journal of Engineering for Gas Turbines and Power, 134 (2012), 117-131.

[3] Khlaief Amor, Boussak Mohamed, Gossa Moncef. Model reference adaptive system based adaptive speed estimation for sensorless vector control with initial rotor position estimation for interior permanent magnet synchronous motor drive. Electric Power Components and Systems, .41(2013), 47-74.

[4] Key Nicole L. Compressor vane clocking effects on embedded rotor performance. Journal of Propulsion and Power, 30(2014), 246-248.

[5] Yi Jiangang. Modelling and Analysis of Step Response Test for Hydraulic Automatic Gauge Control. Strojniški vestnik - Journal of Mechanical Engineering, 61(2015), 115-122. 